\title{
Digital Collections and Digital Collecting Practices
}

\author{
Rebecca D. Watkins ${ }^{1,2}$, Abigail Sellen ${ }^{3}$, Siân E. Lindley ${ }^{3}$ \\ Cardiff University ${ }^{1}$ \\ Cardiff, UK \\ watkinsrd@cardiff.ac.uk \\ University of Southampton ${ }^{2}$ \\ Southampton, UK \\ Microsoft Research ${ }^{3}$ \\ Cambridge, UK \\ \{asellen, sianl\}@microsoft.com
}

\begin{abstract}
Reference is increasingly made to 'digital collections', yet this term encompasses accumulated digital objects of varying form, purpose and value. We review social science literature on material collections and draw from in-depth interviews with 20 people in the UK in order to offer a clearer understanding of what constitutes a digital collection and what does not. We develop a taxonomy that presents three distinct types of digital collection and demonstrate ways in which the affordances of digital environments may facilitate or impede meaningful practices of acquisition, curation and exhibition in each case. Through doing so, we present a framework for design in support of collecting practices and the development of more meaningful and valued digital collections.
\end{abstract}

\section{INTRODUCTION}

Although reference is increasingly made to people's 'collections' of digital content [e.g. 26, 20], little attention has been paid to what is specifically meant by the term 'collection' in such instances. The description 'digital collection' is often used in a very broad sense, to encompass large quantities of accumulated digital 'stuff' of varying form, purpose and value. However, within social science scholarship the term 'collection' holds a more specific meaning and is used to describe groups of acquired possessions with distinct characteristics, including clearly identified boundaries, selectiveness and perceived unity. We identify a need to better understand what constitutes a digital collection (and what does not), and to recognize how practices of digital collecting compare to practices of material collecting.

To address this need, we draw from multiple in-depth interviews with 20 people in the UK, which explored their use, management and experience of digital possessions, and later the notion of digital collections more specifically. In reflecting upon our research findings we are able to (1) distinguish between digital collections

Permission to make digital or hard copies of all or part of this work for personal or classroom use is granted without fee provided that copies are not made or distributed for profit or commercial advantage and that copies bear this notice and the full citation on the first page. Copyrights for components of this work owned by others than ACM must be honored. Abstracting with credit is permitted. To copy otherwise, or republish, to post on servers or to redistribute to lists, requires prior specific permission and/or a fee. Request permissions from Permissions@acm.org.

CHI 2015, April 18 - 23, 2015, Seoul, Republic of Korea

Copyright is held by the owner/authors. Publication rights licensed to ACM. ACM 978-1-4503-3145-6/15/04 ..\$15.00

http://dx.doi.org/10.1145/2702123.2702380 and other types of digital accumulations, (2) introduce a taxonomy of three distinct types of digital collection which involve different experiences, values and collecting practices and are experienced and valued differently, and (3) demonstrate ways in which the affordances of digital environments may facilitate or impede meaningful practices of acquisition, curation and exhibition. In doing so, this paper contributes to HCI by moving towards a clearer vocabulary for discussing digital possessions, and by presenting a framework that can guide HCI design in facilitating particular types of digital collecting practices.

\section{BACKGROUND AND RELATED WORK}

\section{Material Collections: A Review}

In order to frame our findings, we firstly review the understanding of collections adopted within the social sciences. Prior to the 1980s little academic research explored collecting. However, a wealth of literature on the topic has since emerged within, but not limited to, the disciplines of material culture studies, museum studies, consumer research, anthropology, sociology and social psychology. Whilst a comprehensive review of this, now fairly extensive, literature is beyond the scope of this paper, we identify key themes within prior discussions of material collections.

Within this body of work, collections are considered to be a group of possessions with very particular characteristics, although there is disagreement as to what these are. While much debate surrounds the exact definition of collection, one that is widely cited is that of Belk et al. [7, p.180], which is as follows:

"The selective, active, and longitudinal acquisition, possession, and disposition of an interrelated set of differentiated objects (material things, ideas, beings, or experiences) that contribute to and derive extraordinary meaning from the entity (the collection) that this set is perceived to constitute."

Although it is noted that it is not only physical objects that can be collected, prior work has studied collecting almost exclusively in relation to physical objects. From the above definition it is clear that collecting doesn't encompass all accumulations of objects and in particular great pains have been taken to distinguish collecting from the passive accumulation and unselective hoarding of objects $[6,8]$. Collections are distinct in that collectors are highly selective, employing boundaries that distinguish what is and isn't appropriate for inclusion $[4,8,9]$ and following the rule of 'no two alike', avoiding duplicate objects [11].

The objects included in collections are highly varied, including naturally occurring objects such as insects or shells, manufactured or 'orchestrated' collectables [21] such as Beanie Babies or 
Pokémon cards, mundane everyday objects like beer cans and nutcrackers [4], and rare and valuable objects such as fine art and vintage cars [12]. Whilst objects included in collections are highly varied, they are typically non-necessities valued primarily for some reason other than their utility or economic value $[4,6$, 7]. Collections are recognized to become treasured possessions, highly interwoven with people's sense of self, an important point of self-reflection, extension and expression $[3,4,7,8]$.

For many collectors the process of collecting is a pleasurable leisure pursuit and takes precedence over the collectibles themselves. Collectors often describe the thrill of the hunt and the pleasure of discovering a new addition to their collection $[2,4$, 8]. Thus beyond 'having' a collection, 'being' a collector and 'doing' collecting are also important. Although acquisition is the most frequently discussed collecting practice, curating collections by organizing, storing, caring for and maintaining them, and exhibiting collections by displaying them to oneself and to others are also important collecting practices $[4,6,11,12]$. Thus beyond acquisition, collecting involves a complex range of practices which involve a level of controlling, ordering, classifying, managing and ultimately dominating the collection; indeed Akh$\operatorname{tar}[1, \mathrm{p} .40]$ proposes that "the collector reigning over his empire of inanimate objects begins to feel like a demigod."

Although we are limited to only a brief review of collecting literature here, it becomes quickly evident that perhaps the aforementioned difficulty in arriving at an agreed definition of the term lies in complexity and diversity not only in objects collected but also in collectors and collecting. Problems arise from attempting to encompass a range of highly distinct phenomena under the label 'collections' when motivations, practices and meanings are recognized to differ significantly.

For example, it has been acknowledged that collecting is not always intentional and does not always involve striving towards series completion $[4,7,8]$. Pearce [28, p.158] states that "collections can creep up on people unawares until the moment of realization: it suddenly dawns on a woman that the old clothes at the back of the wardrobe constitute an important group of Mary Quant or Carnaby Street dresses, which then in her mind becomes a collection to which she may actively add." However in many accounts, striving towards a perfect collection is key, with collectors aiming for completion or closure and even competing to have the 'best' collection $[4,11]$. Perhaps the most commonly discussed motivation for collecting is mastery, success or competence; here collecting is an opportunity to demonstrate our knowledge, skill and tenacity to ourselves and to others through the successful pursuit of difficult to obtain objects $[4,6,7,8]$.

In other accounts however, collecting is not about pursuit and achievement but about discovering objects incidentally and unexpectedly. For instance, Grasskamp [1983, cited in 4, p.63] proposes that "The art of collecting demands the element of surprise; the collector should not be allowed to know right from the outset what lies in store when he decides for instance to collect radios, even though it is clear that it is only radios he is going to collect." Indeed Belk [4] discusses collecting as a vehicle of modern hedonism, a source of pleasure, desire and fantasy; it has also been described as a series of 'treasure hunts' [Lehrer, 1990, cited in 7]. Such accounts of collecting, defined by suspense, anticipation, excitement and discovery, differ significantly from those in the previous paragraph whereby collections have clear boundaries and an explicit end-goal.

Thus, the literature on collecting shows significant variation in collections, experiences and practices. Prior efforts to bring order to this variance are limited. Scholars have drawn distinctions between the types of objects that form collections. Pearce [29], for instance, draws on factors such as low grade material vs. quality material, unique vs. common, craft-made vs. mass produced. Others compare the types of collectors that build them. Danet and Katriel [11] contrast Type A and Type B collectors, the former having certain affective criteria for choosing items for a collection with the aim of improving it; the latter using cognitive criteria to choose items with the aim of improving their knowledge rather than the collection's beauty; similarly, Belk [4] distinguishes between taxonomic and aesthetic collectors. However, these efforts do not sufficiently account for the variance in accounts of collecting described above. We believe there may be value in building a deeper understanding of the key configurations of collecting, which could simultaneously account for distinctions in the nature of the collection, practices of collecting and the experience of the collector, and aim to do so in this paper.

\section{Digital Collections: A Need for Research}

In addition to this objective, we intend to broaden the focus of research on collecting. Collecting has long been a practice built around material objects, but might we see collections, collecting and collectors in the digital realm too? As people accumulate large quantities of digital objects, questions are raised about the meaning and value that these goods hold, and evidence suggests they may become meaningful objects to which individuals feel strongly attached. Prior research has explored the opportunities and challenges for meaningful possession that digital goods imply [13, 23, $2425,26,34]$, but has not explicitly considered whether these items may be seen as collections.

Indeed, where the term 'digital collection' is used in HCI research $[20,26]$ it is not with reference to the scholarly understanding of collection summarized above. Prior HCI work has tended to consider how users may amass, archive and curate digital "stuff" for other purposes [e.g. 17, 19, 20], rather than for the sake of collecting as understood here. For instance, within work on archiving the emphasis is on effectively storing existing digital possessions for future use [17], as opposed to actively amassing a selection of digital objects as an end in itself.

This paucity of work on digital collections extends beyond $\mathrm{HCI}$, and consequently Belk [5] identifies digital collections as an area about which little as known. Limited prior work indicates that collecting may be much transformed where digital content is concerned. Siddiqui and Turley [31] propose that the majority of accumulated digital content is not regarded as meaningful or selfdefining, whilst Belk [5] has speculated that collections may become less selective in the digital realm since we are able to create, acquire and keep large amounts of digital stuff, relying on searching and sorting to provide coherence and unity. Thus 
whilst digital collections have yet to receive substantial empirical exploration, there is some indication that digital collecting may take on new and distinct forms. However, we lack a substantial understanding of how these practices might unfold. Do people collect digital objects? What might a digital collection consist of? How might digital collections compare to material collections? These are the research questions we aimed to explore.

\section{RESEARCH DESIGN}

Over a 2 year period (June 2012-July 2014) multiple in-depth interviews took place with 20 people in the UK in order to explore the ways in which they experienced, used and managed their digital possessions. This study adopted an emergent design, involving an iterative process of data collection, analysis and interpretation that enabled a gradual narrowing of the study's focus and aim, with emerging themes explored in increasing depth.

\section{Participants}

We conducted 41 interviews with 20 individuals (aged 17-80, 12 women and 8 men). Our aim was not to produce a 'representative sample', but to select participants who would generate a breadth of experiences. Screening questions asked via email and telephone calls enabled participants to be selected purposively. Participants spanned generations and life-stages and had diverse backgrounds. Our emphasis, however, was also on heterogeneity within participants' engagement with technology and in particular with digital objects. For instance participants included an exIT worker who described herself as a 'techie', a computing student specializing in hacking, an experienced beauty blogger and an avid MMORPG gamer, alongside participants who described themselves as having a fairly functional relationship with technology and worried they would have little to say on the matter. Sampling purposively in this way produced highly varied accounts of digital possessions, but nevertheless significant themes began to emerge within participants' stories.

\section{Data Collection, Analysis and Interpretation}

In unstructured, in-depth interviews, lasting between one and three hours, participants were asked to tell the first author about their digital possessions and where possible to show them (via laptops, mobile phones, tablet devices, gaming consoles, etc.). The aim was to cover areas key to participants' relationships with their digital possessions, rather than imposing an a priori set of topics. Participants were prompted to elaborate, where necessary, in order to produce rich, descriptive accounts. All interviews were transcribed in full, and subject to hermeneutic analysis $[32,33]$, moving between ideographic analysis of individual interview transcripts and cross-case analysis in which common themes were identified across participants' accounts.

Up to three interviews were conducted with each participant over a two year period, in order to understand and document changes over time. An iterative process of data collection, analysis and interpretation meant that where prominent themes began to emerge the researcher was able to prompt participants to elaborate on these subjects in greater depth in later interviews. For instance, in follow up interviews participants were asked to discuss those digital possessions that they might consider a 'collection'.
Often participants would list content and ask whether the researcher would consider this a collection - a question that was never answered directly and always met by the question 'Do you consider it to be a collection?' Thus interviews were guided by emic rather than etic definitions of collection; care was taken not to assess during the interview whether content discussed would fit scholarly definitions of collecting, but to discuss fully all content that participants described as such. Data collection concluded once a point of theoretical saturation was reached. In total over 68 hours of interview data was collected, with an average of over 3 hours spent with each participant.

\section{A TAXONOMY OF DIGITAL COLLECTIONS}

During the interviews participants described a range of digital content as collections, including (but not limited to) objects in videogames, digital photographs, social media profiles, eBooks, digital music, and blogs. Participants' colloquial use of the term 'collection' often encompassed broader types of accumulated and gathered content than would conform to established theoretical definitions. Using this theoretical lens we point to two kinds of practices that participants referred to as collections but which do not fit established understandings, before focusing in the rest of the paper upon those practices which adhere more closely to a strict definition from the existing literature.

Firstly, in existing definitions, a collection consists of externally produced content that must be acquired, whether it is mass produced (e.g. trading cards), produced by another individual (letters written by a celebrity) or naturally occurring (e.g. shells). Personally-created content does not fall under this rubric. Therefore while it is common, for example, for people to refer to their 'photograph collections' (both digital and material), individuals' role in producing rather than acquiring these photographs distinguishes these digital accumulations from digital collections. Likewise, tweets, blog posts or Facebook pages might be classed as content that has been created or crafted, rather than collected. Using established definitions, then, user-generated content, which is considered in discussions of personal digital archives $[17,20]$ and online exhibitions [16], are not collections.

Secondly, a collection is considered as an end in itself, whether this perception emerges during or following its assembly. A group of objects that is gathered simply to serve as a means to another end, and continues to be valued only for this purpose, would not be classed as a collection. A common example within participants' accounts was Pinterest boards whereby, consistent with previous research [19], 'pins' were gathered as resources to aid in the achievement of tasks such as decorating a home or planning a wedding. Although such a board might come to be valued as a collection that is an end in itself, this was not found to be the case for our participants. Similarly, participants described completing collecting tasks in videogames, gathering items out of necessity to progress within the game. In both cases, the objects in question are regarded as resources for some other purpose, rather than collected for their own sake.

Having argued that some digital accumulations are more usefully understood as distinct from collections, we now consider digital 
collections present in participants' accounts that are more consistent with established theoretical definitions. Using the lens of collecting developed in prior work, we consider digital collections to consist of sets of acquired objects that are selective, have distinct boundaries, are valued for their unity, and may be actively added to. However, as with material collections, we found digital collections, collectors and collecting practices to be highly varied. We identify three key 'types' of digital collection (pursued, evolving and emerging), outlined in Figure 1 and described in greater depth below. As previously noted, prior work has not brought coherence to the varied accounts of collecting in the literature. Here we highlight common configurations of collections (their boundaries, desired end-state and meaning), collectors (their experience), and collecting (practices of acquiring, and later curating and exhibiting collections), which presents a novel contribution in itself.

Pursued collections draw the clearest parallels with existing literature on material collections. Both the boundaries and the desired end-state of a pursued collection are clear, whether defined by the market or by individuals. Objects outside of these boundaries are likely to be rejected from inclusion in the collection, whilst objects within these boundaries are actively sought. The collector enjoys the thrill of the hunt, with each successful acquisition producing feelings of achievement and mastery. Indeed, pursuing such collections provides a sense of purpose, and the collection itself becomes a symbol of the collector's skill, knowledge and competence, particularly when objects are rare or difficult to obtain. Pride is taken in this collection, and there may be a desire to display it in a prominent way that recognizes its status. Whilst a great deal of literature on material collections falls into this category, pursued digital collections occurred least frequently in our data, and were most evident in videogames.

An example of a pursued collection comes from Richard, a 22 year old sales executive and regular Xbox gamer from Cardiff, who described his car collection in racing videogame Forza 3.

" [I had] one from each manufacturer. And the highest level one from each manufacturer I could get. So literally I had a whole garage that could beat anything. So if my mate came on and said 'let's race with Ferraris' for example, my Ferrari would be upgraded to such a level where there's no Ferrari he could have picked that would've beaten me."

Although some players might strive to collect every car in the game, or perhaps every car by a particular manufacturer, Richard aimed to own one 'top' car from each manufacturer that was fully upgraded. Thus his collection had both clear boundaries and a defined end goal that was actively pursued. Richard strove towards his ideal collection for almost a year, earning in-game currency by racing less expensive, less desirable cars in order to finally afford his perfect collection. Time was then spent upgrading the performance of each car by purchasing new and better car parts and tuning the engine for better performance. It became evident that Richard's collection was highly selective; although there were a number of other cars in his Forza garage, only the 'top spec' cars were considered part of his collection. Additionally he adhered to the 'no two alike' rule [11]; where he received an in-game prize of a car that he already possessed he gifted this duplicate to a friend. Richard discussed his car collection with pride; it was difficult to build and represents his skill at racing within the game. However, as we shall see, the ease of acquiring many digital items meant such collections were uncommon.

\begin{tabular}{|c|c|c|c|}
\hline & $\begin{array}{l}\text { Pursued } \\
\text { Collections }\end{array}$ & $\begin{array}{l}\text { Evolving } \\
\text { Collections }\end{array}$ & $\begin{array}{l}\text { Emerging } \\
\text { Collections }\end{array}$ \\
\hline Example & \begin{tabular}{|c|} 
Richard strives towards \\
a pre-defined, 'unbeata- \\
ble' car collection in \\
videogame Forza, ac- \\
tively pursuing new ad- \\
ditions to his collection \\
\& eventually reaching a \\
point of completion
\end{tabular} & $\begin{array}{l}\text { Ben is continually } \\
\text { discovering new } \\
\text { songs and albums to } \\
\text { add to his evolving } \\
\text { iTunes collection, } \\
\text { but has no desire } \\
\text { for, or vision of, a } \\
\text { completed } \\
\text { collection }\end{array}$ & $\begin{array}{l}\text { Wendy does not } \\
\text { consider her } \\
\text { eBook purchases } \\
\text { as 'collecting', } \\
\text { however as they } \\
\text { accumulate they } \\
\text { come to be per- } \\
\text { ceived as a col- } \\
\text { lection }\end{array}$ \\
\hline \multirow[t]{2}{*}{ Collection } & $\begin{array}{l}\text { Characteristics } \\
\text { Clear boundaries and } \\
\text { envisaged end state }\end{array}$ & $\begin{array}{l}\text { Characteristics } \\
\text { Clear but flexible } \\
\text { boundaries and no/ } \\
\text { vague envisaged } \\
\text { end state }\end{array}$ & $\begin{array}{l}\text { Characteristics } \\
\text { Loose bounda- } \\
\text { ries, no envis- } \\
\text { aged end state }\end{array}$ \\
\hline & $\begin{array}{c}\text { Meaning } \\
\text { Collection represents } \\
\text { collector's skill and } \\
\text { knowledge }\end{array}$ & $\begin{array}{c}\text { Meaning } \\
\text { Collection holds au- } \\
\text { tobiographical } \\
\text { value, may repre- } \\
\text { sent taste }\end{array}$ & $\begin{array}{l}\text { Meaning } \\
\text { Holds autobio- } \\
\text { graphical value, } \\
\text { and may repre- } \\
\text { sent taste }\end{array}$ \\
\hline Collector & $\begin{array}{c}\text { Experience } \\
\text { Achievement and mas- } \\
\text { tery, as well as a sense } \\
\text { of purpose }\end{array}$ & $\begin{array}{c}\text { Experience } \\
\text { Experiences feel- } \\
\text { ings of excitement } \\
\text { and anticipation }\end{array}$ & $\begin{array}{l}\text { Experience } \\
\text { Act of collecting } \\
\text { itself is passive }\end{array}$ \\
\hline \multirow[t]{2}{*}{ Collecting } & $\begin{array}{l}\text { Acquisition } \\
\text { Goal driven and pur- } \\
\text { poseful 'hunt' for de- } \\
\text { sired additions }\end{array}$ & $\begin{array}{c}\text { Acquisition } \\
\text { Anticipation and ex- } \\
\text { citement as new ad- } \\
\text { ditions are discov- } \\
\text { ered, often unex- } \\
\text { pectedly }\end{array}$ & $\begin{array}{l}\text { Acquisition } \\
\text { Objects are ac- } \\
\text { quired without } \\
\text { collection in } \\
\text { mind }\end{array}$ \\
\hline & $\begin{array}{l}\text { Post-Acquisition } \\
\text { Collection may be cu- } \\
\text { rated and/or exhibited }\end{array}$ & $\begin{array}{c}\text { Post-Acquisition } \\
\text { Collection may be } \\
\text { curated and/or ex- } \\
\text { hibited }\end{array}$ & $\begin{array}{c}\text { Post-Acquisition } \\
\text { Collection may } \\
\text { be curated and/or } \\
\text { exhibited }\end{array}$ \\
\hline
\end{tabular}

Figure 1. Taxonomy of digital collecting configurations.

Evolving collections, in contrast, have more flexible boundaries and are not pursued by individuals striving towards a perfect collection, but rather evolve gradually as new additions are discovered. Here there is a sense of excitement and discovery since there is no way of knowing what the next addition to the collection might be or when and where it will be discovered. Rather than skill, these objects represent collectors' personal taste and interests, and may hold autobiographical value. An example of this comes from Ben, 41, a graphic designer from Cambridge who DJs in his spare time and possesses large collections of records, CDs and mp3s. His collection of digital music stored within iTunes, which he estimates to be worth over a thousand pounds, has been continually evolving for almost a decade but not towards a pre-defined end state. Rather, Ben is continually discovering new music to add to his collection.

"I'll make lists of stuff I hear on the radio, then go and download that [...] If I hear something through Spotify I like, I'll tend to 
email the name of the track and the author to myself and then go and buy that at home. [...] [I tend to delete] things that I listened to again and didn't think they were that great the second time around, or maybe I just lost interest in that particular type of music. And in some instances, there was a particular genre of music I didn't listen to as much, and I got myself an external hard drive and then took all of that particular type of music off iTunes and then put it on that hard drive"

Discovering new music is key to Ben's account, and whilst he could continue to listen to these tracks via Spotify he feels it is important to add these songs to his collection. Whilst his collection is extensive it is carefully curated, with meaningful categories imposed and less favoured items either deleted or removed and stored separately. Ben explains that his digital music collection prompts reminiscence as songs and playlists remind him of past DJ slots and music events. Thus we see that Ben's evolving digital music collection is similarly highly valued, yet differs significantly from Richard's pursued car collection in Forza in meaning, practice and experience.

The third category, emerging collections, is distinct from pursued and evolving collections in that this kind of collection initially emerges as a by-product of some other activity. The majority of collections seem to begin as emerging collections; as noted by Belk [4] and Pearce [28], objects may only later be recognized as a collection to which items are then more actively added (at which point the collection becomes an evolving or pursued collection). Emerging collections are perhaps the most overlooked category of collection in material collection literature, although exceptions do exist. Shankar [30] illustrates that even when not actively 'collected', accumulated record collections become important and symbolic archeological representations of music consumption over time. Another example might be a traveler who comes to see the stamps on their passport as a meaningful collection representing countries visited, but does not actively travel abroad with the primary aim of adding new stamps to this collection. Emerging collections were most prominent in our participants' accounts of their digital collections.

An example comes from Alice, a 30 year old PR consultant and mummy blogger who studied English Literature at university and remains an avid reader. Indeed, one of the bedrooms in her home has been converted into a library. Having recently received a Kindle e-reader as a gift, Alice is a convert; while she still loves owning and displaying physical books she can't deny the convenience offered by eBooks. Alice considers both her eBooks and material books as collections (although her material books are more highly prized), yet she does not purchase eBooks with the primary intention of adding them to her collection. Rather she downloads eBooks to read, and later reflects on them as an accumulated collection that summarizes her e-reading history. However we shall see that Alice perceives this collection as less significant than her material books since exhibition is problematic.

\section{Summary of Framework}

To summarise our argument so far, our participants' meaningful digital collections can be organised into three key 'types'. These are exemplified by the three examples provided, however a range of other digital objects were also discussed as collections. The taxonomy presented in Figure 1 presents a useful framework in acknowledging that distinct types of collections exist, which are associated with highly varied meanings, experiences and practices. The same type of object may fall into different categories, depending upon how it is used and interpreted; indeed, collections may transition between the categories presented here, as meanings and practices change. Emerging collections may become evolving collections as individuals come to actively acquire new additions, and evolving collections may become pursued collections, as more explicit boundaries are established and a clearer end goal envisaged. It is worth noting that these categories apply not only to digital collections; much of the literature on material collections falls into one of the above collection types. Thus, our taxonomy presents a framework for imposing order on prior literature. We shall see in the following section, however, that a number of issues arise which make the types of highly meaningful, sacrilised collections described by Belk [4], Pearce [28] and others difficult to achieve in the digital realm.

\section{DIGITAL COLLECTING PRACTICES}

In our analysis it became quickly evident that many of the practices that have been documented as making material collections so precious can be difficult or problematic in digital collecting. Here we review some of the most prominent distinctions that emerged in practices of acquiring, curating and exhibiting digital collections, drawing from the three examples provided above (collections of digital music, digital cars and eBooks).

\section{Acquisition}

The pleasure of adding to material collections is such that people may delay their completion by extending boundaries, or begin new collections [4]. Acquisition is typically discussed as active and goal-driven, with much pleasure found in the thrill of the hunt, or as driven by anticipation and the thrill of discovery. To what extent might acquiring digital goods afford the same thrills?

\section{Thrill of the Hunt}

Existing work on material collecting describes the experience of the 'thrill of the hunt'. Where collections are pursued, complex practices of acquisition present a challenge that is relished, since it provides an opportunity to demonstrate skill and knowledge, and to experience a rewarding sense of achievement. Belk [4, p.89] proposes that "rarity is prized because it is not enough to succeed if everyone else succeeds as well". Collecting must be moderately difficult in order to be satisfying and generate pride.

However, in digital collecting, the hunt for new additions rarely presents an adequate challenge. A key advantage of many digital goods is their ease of acquisition; these items are infinitely reproducible and never 'beyond reach' or out of stock (unless artificial scarcity is employed). An exception within participants' accounts was collections within videogames, echoing the findings of Molesworth and Watkins [23] that a sense of achievement is gained through accumulating and crafting digital possessions within videogames. This is evident in Richard's pride when describing his unbeatable car collection within Forza, a collection he had built up through hard work and skill. During his interview he discussed desired cars he was working towards, alongside the 
satisfaction felt with each new acquisition. Richard's account illustrates that the thrill of the hunt can be experienced in the digital realm if acquisition presents a significant challenge.

Notably, within our dataset this experience was limited to videogames. Objects that were easily acquired did not provide a sense of achievement and did not represent skill, knowledge or status. For instance, a large record collection would likely involve significant commitment to searching for and acquiring rare records but, in contrast, participants noted that finding and downloading a song is not difficult and nothing to be proud of. Ben's CD and record collections were until recently given pride of place in his home, and he enjoyed their visibility. He is proud of his collection of CDs and records, which took significant effort to achieve, something that is not the case with his digital music collection:

"I was quite proud that that was up there actually in my living room so other people could see it [...] I think with records they're so much harder to get, well they are nowadays anyway, there's certain records that are super hard to get hold of now [...] [people] may see this record and go 'wow you've got that on vinyl.' Whereas, you know, they may well have that on iTunes [laughs] they're not that bothered about their iTunes version of it, they would really like a seven inch record of this particular piece of music [...] It's to do with the effort of finding it. It's a super rare piece of music, extremely hard to find, you know, you'd have had to dig through a whole pile of crates in a record shop to get it."

The effort involved in building Ben's physical music collection grants it an elevated status that has warranted practices of display. He explains that this collection would be difficult to replace since it contains rare and valuable items that would be difficult to find again. In contrast, his collection of music within iTunes is more replaceable-although he would be upset to lose it, it would be fairly straightforward to repurchase these mp3s. Practices of acquisition may shape the meaning of digital collections; so easily acquired are Ben's mp3s that they do not demonstrate skill and consequently do not warrant display or evoke pride.

\section{Thrill of the Find}

In contrast to the thrill of the hunt, evolving collections are characterised by the thrill of the find. Here additions are not actively sought, but are discovered and added to the collection. Hence the chance of discovery is key; McCracken [22, p.93] notes that when their acquisition is uncertain "collectibles make it possible once again to dream", whilst Belk [4] found that travelling to new places offered collectors the additional excitement of potentially discovering new objects. Might practices of digital collecting offer the same sense of excitement and anticipation emerging from the chance of discovery?

Becky, a 17 year old student from South Wales, has recently begun collecting old vinyl records. Becky's description of searching for records illustrates the anticipation of finding new records and taking them home to add to her collection - each visit to a car boot sale or charity shop is filled with potential for discovery.

"It's kind of exciting because I love seeing a box of loads of records and just choosing which ones I want. Like, I love just looking through them all, and the smell of them as well. Yeah, it's just quite an enjoyable experience, I could sit and just look through vinyls, not even wanting to buy any [...] I'm always excited to go home and play it and just to listen to it, especially when it's someone I haven't heard of or I've never heard their music before"

Evident in Becky's account of record collecting was a desire to acquire more, however there was also a desire to acquire new additions in a particular way. Whilst she recognizes that she could have more easily acquired records via platforms such as eBay she prefers the enjoyable experience of visiting places where she might unexpectedly stumble across an exciting new addition to her collection. Thus the practice of collecting emerges as perhaps more important than the collection itself, producing feelings of excitement and anticipation. In contrast, in her account of searching for digital music it appears that acquisition is simply a functional, rather than enjoyable, practice.

'It's not as exciting as buying a record, 'cause a lot of the time I'll have heard of the person. I never really, like, some way or another I've heard of that person that I'll be downloading new music from, whereas a lot of the vinyls, 'cause they're so old I haven't heard of a lot of the artists [...] you can download it straight away, whereas you buy a vinyl you have to wait until you get home to play it, it's not, you can't just instantly hear it, so it's a bit more of an experience",

Becky feels there is less opportunity for serendipitous discovery during her current practices of acquiring digital music, whilst the opportunity for instant gratification produces less sense of the pleasurable anticipation that makes record collecting so appealing. However, Ben points out that in purchasing music from iTunes there is the potential to discover new and exciting music:

"There's a really good feature on iTunes actually, so that if you put a search in for a piece of music, and you start to play it, there's a list that appears at the bottom of album covers, and that shows you what other people have bought [...] So that helps to expose you to new music [...] I've bought absolutely piles of music through that feature, just because it's exposed me to stuff"

Similarly, Alice describes herself as addicted to the Kindle Store which she browses for new eBooks, waiting for best prices and discovering new content. Whilst digital collections may lack the element of chance evident in Becky's account of record collecting, due to lack of scarcity, browsing for digital music and eBooks can remain an enjoyable experience with the anticipation of either a bargain or the discovery of new, exciting items.

\section{Curation}

Beyond acquisitional aspects of collecting, what curatorial practices might people engage in in terms of caring for, managing and ordering digital collections in meaningful ways? Typically items in material collections are placed out of use, indeed they are valued "not because of any inherent use value but precisely for their non-use value" [4, p.62]. The suggestion that the stamps in their collection should be used to post a letter would, to a stamp collector, seem absurd. However, even prized digital collections remained in use by our participants. Digital music collections were listened to, collections of eBooks were read and Richard's 
treasured collection of cars competed in races. We might speculate that practices other than removal from use signify a collection's meaning in the digital realm, such as storing objects together and separately from other items, and organizing them in personally meaningful ways. However, participants did struggle to bring order to digital collections in a way that recognized their elevated status and even their unity. We propose that where individuals are unable to perform such curatorial practices the meaning of digital collections can be eroded.

\section{Organizing}

The ways in which possessions are stored and organized enables people to mark, maintain or transform their meaning. Collectors are acknowledged to engage in a series of rituals to mark their collections as sacred. For instance they may separate them from more mundane artefacts, display them prominently or provide them with special care and attention $[4,7,15]$. However our participants struggled to order their digital collections in meaningful ways. Whereas in previous work, acts of organizing material possessions are seen to produce and stabilize categories of meaning [14], it became evident that participants rarely organized their digital collections since such practices were often performed instead by software. Often there is limited choice as to how collections can be organized; for instance Richard explained that although he can choose to sort his cars in Forza by manufacturer or racing class, he is unable to impose his own classifications. He would not, therefore, be able to separate his prized collection of high spec cars from the functional cars in his Forza 'garage'.

Eve, a 35 year old artist and postgraduate student, explained that she carefully orders her record collection thematically, grouping what she perceives to be similar music together and storing some of her least favored records separately. Through this act of separating she recognizes and enforces distinctions in meaning, and explains that since her sizable collection of records "can be overwhelming, the way you personally want to organise things is really important to kind of make sense of it." Such practices became difficult in managing her digital music collection, however.

\begin{abstract}
"the thing I don't like about iTunes, with this whole alphabetical organising thing, that means you can't hide stuff so easily. So say the album you want to hide begins, or the group begins, with A, they're there every time you open up your iTunes"
\end{abstract}

Eve feels that iTunes doesn't enable her to organize her digital music collection as she desires, and consequently she feels that she has less control over it than her record collection. This lack of control became particularly evident to her when she changed computers, meaning that her digital music collection moved to an updated version of iTunes where its prior order was changed.

"You get a new version of the software and it's mixed it all up, you regret that kind of having to re-organise it all or put it all back to how you used it before, and if you can't use it the way you used it before that's really frustrating. [...] with a digital collection of music, because of the way you upgrade it and it organises things, it organises things differently, I don't really feel it's mine in a way [...] when you open up your computer and your collection of music isn't organised the way it was when you last opened it, that kind of makes the feeling of ownership not quite as... you don't feel you own that [...] I've got quite a substantial amount of music on my laptop, so I guess in a way I do have a collection, but it doesn't feel quite like it because I don't have this way of organising it in the way I'd like."

In contrast to feelings of control, mastery and dominance associated with material collecting $[4,7,8]$, here we see that Eve is struggling to achieve any real sense of control over a collection that she is unable to impose any meaningful or lasting order over.

\section{Uniting}

Often collections of content were bound to particular contexts or devices and participants had difficulties moving content around. For instance, videogame content was left behind on old consoles and within previous versions of games, whilst some participants struggled to move music collections between devices. Gregson [15] describes collections as perhaps the most enduring of possessions, however here we see that digital collections may not persist outside of certain contexts. For instance, Richard explains that when he purchased Forza 4, the more recent iteration of the videogame, he had to leave behind his treasured collection of cars; he was unable to transfer his collection to the new version of the game. In Forza 3 Richard had accumulated a total of 100 cars including a top car from each manufacturer, however in Forza 4 he has only 14 . He talks about 'losing' these cars (even though they are still accessible in the old game) and explains that although he has tried to rebuild his collection in the newer version of the game the cars never feel quite the same since he feels that they do not have the same history. Richard's 'loss' made him less motivated to collect cars in the later iteration of the game; he plans to simply focus on the racing aspect of the game instead.

Other participants described similar instances. Becky, for example, explains that after receiving a new laptop for Christmas she is struggling to transfer her old content to her new device due to broken USB ports. She has uploaded some content to Facebook (photos) and sent others via email (e.g. CVs) with plans to redownload them onto the new laptop, however the majority of content (including her digital music collection) is left behind on her old device. She explains that she doesn't know how to transfer this data, and therefore this collection is effectively 'trapped' on her old computer and iPod. Becky is unable to connect the iPod to her old laptop since the USB ports are broken, but worries that if she plugs it into her new device it will sync automatically to the (empty) iTunes library and that she will lose her music. Consequently Becky is planning to purchase a new iPod to store her new music.

"I think I'll have to get a new iPod, because I think if I plugged mine in now all my old music would go [...] I don't want to risk putting it on my old iPod, I'd rather get a new one for my new music and keep my old iPod for all the old music. [...] it would be annoying because they wouldn't be all, you can't access them all at once, you'd have to keep changing iPods"

Becky is struggling to unite old content with new content. Similarly Richard explains that he is unsure how to unite his iTunes library with music purchased from the Google Play Store on his 
phone. Prior work indicates that keeping track of digital possessions across platforms can become problematic [24, 25]. Here, participants struggled to move their collections from device to device or videogame to videogame, and consequently we observed trapped collections left behind and fragmented collections spread across locations. Participants, even 'digital natives' such as Becky, lacked the technological understanding necessary to unite their collections as meaningful wholes.

\section{Exhibition}

Social scientists have long recognized that in displaying objects we both communicate to others aspects of who we are (or would like to be perceived to be) and reaffirm our own sense of self. In Shankar's [30] study of record collections, he proposes that records (and we might speculate also, books, films and other collections) may become an archaeological record of our past consumption, telling us something about who we are and who we once were, and communicating this information to others. Might digital collections serve the same self-reflective and self-presentational purpose? How do people exhibit their digital collections to themselves and others?

\section{Self-Reflection}

Reflection on digital collections in their entirety was largely absent from participants' accounts; it seemed that their digital collections often disappeared when not in use. Often these collections were not stored and displayed in an enduring way that facilitated easy reflection. For instance, Alice explained that she enjoyed browsing her library of material books, sometimes flicking through books and reminiscing. Her book collection represents her taste in literature, but also holds significant autobiographical value; books she studied at University contain annotations and remind her of a period in her life. Alice's eBooks, on the other hand, were described as disappearing into the depths of her Kindle after reading and were rarely reflected upon.

"I think when I've finished a book on the Kindle, it is probably just archived and discarded and I doubt that I'd look at it again, whereas I've got loads of bookshelves upstairs with all my books on [...] I love my books. And I do like going and browsing, like sometimes I'll pick up a book that I read say ten years ago and re-read it if I remember I really enjoyed it, so I think that's where the relationship's different. Although I know what I've got on my Kindle I don't view it so much as a possession afterwards, once it's been read [...] I'd like to have the ability to read it on the Kindle just for the ease and practicality, but then I'd like to have the actual physical book to put on my bookshelf to keep, and to remind me that it's there"

Consistent with prior work $[26,10]$, it becomes evident that Alice's eBooks simply don't have the presence of her material books, which through being stored and displayed prompt acts of browsing, reminiscing and reflecting. In contrast, her eBook collection only presents itself when summoned, via an e-reader which displays one or a few items at a time. Similarly, Richard explained that whilst it is easy to scroll through each car in his collection, he has no way to view the entire 'garage' as a whole. Current design seems to enable easier engagement with single digital possessions than collections. It can be difficult to grasp the scale of digital collections in their entirety, as they lack the presence that makes collections ideal candidates for self-reflection.

\section{Displaying to Others}

Displaying collections to others is key in many accounts of material collecting; Belk [4] proposes that when collections are presented to others the collector is in essence presenting themselves for evaluation. Prior research indicates that digital objects may communicate meaning to others, expressing skill, status and group membership [18]. However, digital objects present both challenges and opportunities for display. Hogan [16] illustrates that the digital realm may provide opportunities for enduring and highly visible exhibitions via social media, however, digital objects are not always characterized by enduring visibility. Participants described their material music, book and film collections as a talking point amongst friends, but digital collections were less socially visible. For instance, Richard had little opportunity to show his car collection to others, even when playing online.

"They can see how many races you've won, what level you are and whatever else. How much money you've got. But they can't see how many cars you've got or anything like that. And if you've downloaded a car that they don't own it just shows as a stock shaped car, it doesn't show the visual part of it, it's just a black shape driving around"

Furthermore, Eve notes that where friends can see her collection of digital music, her inability to organize and exhibit as desired results in a less meaningful or representative display.

"Every time I open iTunes, say if somebody else is there, they can see alphabetically what I've got, but it's not necessarily my favourite albums, whereas if I had a way of organising them, so like, if my favourite albums came up first, then it'd be more representative of the music I like. [...] there should be some personal decisions there about how you display them."

Here we see that digital collections not only lack social visibility, but where exhibition is possible, lack of curation can make such displays less meaningful. Material collections are often discussed in terms of identity, extending the self and shaping the self-definition of a collector [3, 4, 7]. Where digital collections are not viewed by oneself or by others they may become less clearly interwoven with the collector's sense of self.

\section{DISCUSSION}

We shall now consider in turn each of the research questions the study sought to answer. Firstly, do people actively collect digital objects? Prior research has discussed digital possessions at a broader level $[24,25,26]$, and we have noted that where the term 'digital collection' is used in HCI it tends to refer to accumulated digital 'stuff' rather than collections as a distinct phenomenon. Digital accumulations may take a variety of forms; from digital clutter which simply accrues unintentionally (e.g. emails, metadata, browsing histories) to more carefully curated digital archives (e.g. folders of photographs and work documents). However in this paper we have demonstrated that digital collections present a distinct type of digital possession. Digital collections consist of sets of acquired digital objects that are selective, have distinct boundaries, are valued for their unity, and are often 
actively added to by the user. However, there are different types of digital collection, just as research on material collections points to variance. We have identified three kinds of digital collection, which share some, yet not all, of the characteristics of physical collections. We have defined these as pursued, evolving and emerging, and have shown that collecting practices as well as the meaning and value attributed to collections varies across these types. Thus, people do actively collect digital objects, and distinguishing these digital collections from other digital accumulations moves the $\mathrm{HCI}$ community towards a clearer vocabulary for discussing digital possessions.

Secondly, what might a digital collection consist of? We have focused on three examples discussed by participants: digital music, digital cars within a videogame and eBooks. However, these examples are illustrative rather than exhaustive and our research participants identified a broader array of digital objects that might be considered collections. Thus, consistent with prior work on material collections, we identify collections by the way they are experienced by the user and the performance of collecting practices, rather than by particular categories of object. Further work might extend the understanding offered here by focusing on specific contexts (quantified self systems, virtual worlds).

Finally, how might digital collections compare to the material collections previously documented? What is clear from this work is that individuals can both enjoy and attach importance to their digital collections, yet the tools at hand often fail to provide adequate support for the full range of value and meaning that they might otherwise derive from them. The analysis presented above presents a number of implications for design in support of collecting practices and more valued digital collections. In doing so, it extends prior work on how design may enable more meaningful relationships with digital possessions [e.g. 24, 25, 26].

A first set of implications relates to practices of acquisition and the subsequent value attached to digital objects by users. While recommender systems present opportunities for surprise and novelty, the nature of acquisition in the digital world means that, outside of videogames, there is little opportunity for the challenging pursuit of digital goods, a factor that has been linked to experiences of mastery, success and competence in material collecting. Making things challenging to acquire by demanding a level of skill, knowledge or effort may enhance the value of collections. Examples of how this might be accomplished in the digital realm include a mobile app developed in a zoo setting, where collecting was tied to physically visiting exhibits [27]. Likewise, attending a concert could unlock exclusive content on an mp3. Alternatively, design for challenging acquisition could draw on uniqueness and rarity. For instance, 'first edition' eBooks may retain unique covers and resist changes to their appearance brought about by software updates, developing a dated appearance that sets them apart from others and makes visible the fact that the collection contains unusual, rare, or difficult to obtain items.

A second set of implications involves designing more flexible tools for managing digital collections, enabling users to mark their elevated status by separating them from other possessions and to impose their own structures of meaning. Many applications impose organizational schemes that can undermine individuals' sense of control over their digital collections, and make it difficult for users to organize collected items across applications, devices and platforms. The result of this is trapped and fragmented collections, which make it difficult for users to maintain the entirety of their collections, and their existing order, as they shift across technologies. An approach that recognizes the importance of curatorial work in conferring meaning, and the persistence of a whole collection, may increase the stability and endurance of digital collections, and enable a greater sense of control and mastery on the part of the collector.

Finally, the findings point to the fact that, like physical collections, digital collections can and do play a role in personal reflection and public identity. This could be better supported by providing ways to view collections in their entirety, and to produce more enduring, socially visible exhibitions. Crucial here is underpinning ways for users to create a public face for their collections, whether this means more visibility in the digital realm, or more opportunities for display in the physical world. New kinds of displays, appliances, and even wearables could allow for the showcasing of collections. In increasing the visibility of digital collections, we may enrich the personal and public meanings they come to hold, and consequently their self-expressive and self-reflective value. Furthermore, we build on Odom et al's [25] suggestion that digital patina could be used to signify provenance and so play a role in personal reflection. A digital good might indicate that, for example, it was downloaded whilst on holiday or gifted by a friend, thus building an autobiography of use and underpinning a greater level of personal meaningfulness.

While the recommendations provided so far speak to digital collections in general, we can also draw on the taxonomy we have proposed to understand how design might differentially support collecting practices for pursued, evolving and emerging digital collections. In designing for pursued collections, for instance, we could draw on the importance of a clearly defined end goal and offer users the option to construct a template for an ideal "set" of objects that they hope to acquire. In contrast, evolving collections are characterised by a desire for surprise and novelty and might benefit from creative recommendations. Furthermore, design may have the potential to transition collections between categories by shaping collection practices. For instance, transition from an evolving to a pursued collection might be supported by enabling users to impose clearer boundaries and to envision a perfect collection, whereas transition from an emerging to evolving collection could be supported by design for surprise and novelty. Furthermore, we may aid recognition of other accumulated possessions as emerging collections by providing tools for curation and exhibition that can help shape their perceived value.

\section{Conclusion}

This paper advances emerging work on digital possessions by defining digital collections as distinct from other types of digital accumulations such as digital archives and clutter. We use the lens of collecting in the physical world to explore how the digital world is different, and how existing tools may 
undermine the value users seek from collections and the drive to collect. We highlight the challenge of acquisition, the imposition of the user's own meaning structures, and the potential for selfexpression and personal reflection as key factors that could be better supported. Further, our analysis leads us to introduce a taxonomy of three distinct types of digital collection which can further inform HCI design by facilitating relevant collecting practices for each type, as well as for transitions between them.

\section{REFERENCES}

1. Akhtar, S. Objects of Our Desire: Exploring our Intimate Connections with the Things around Us. New York: Harmony Books, 2005.

2. Baker, S.M. and Gentry, J.W. Kids as collectors: a phenomenological study of first and fifth graders. Advances in Consumer Research 23, (1996), 132-137.

3. Belk, R.W. Possessions and the extended self. Journal of Consumer Research 15, 2 (1988) 139-168.

4. Belk, R.W. Collecting in a Consumer Society. Psychology Press, 1995.

5. Belk, R.W. Extended self in a digital world. Journal of Consumer Research 40, 3 (2013), 477-500.

6. Belk, R.W. "Ownership and Collecting," in Randy O. Frost and Gail Steketee, eds., Oxford Handbook ofHoarding and Acquiring, Oxford: Oxford University Press (forthcoming).

7. Belk, R.W., Wallendorf, M., Sherry, J.F. Jr. and Holbrook, M.B. Collecting in a consumer culture. In Belk, R.W. (Ed.), Highways and Buyways: Naturalistic Research from the Consumer Behavior Odyssey (pp. 178-215). Association for Consumer Research, 1991.

8. Belk, R.W., Wallendorf, M., Sherry, J.F. Jr., Holbrook, M.B. and Roberts, S. Collectors and collecting. Advances in Consumer Research, 15 (1988), p.548-553.

9. Bianchi, M. Collecting as a paradigm of consumption. Journal of Cultural Economics 21, (1997), 275-289.

10. Brown, B. A. T., Geelhoed, E., Sellen, A. J. (2001). The use of conventional and new music media: Implications for future technologies. INTERACT. Tokyo, Japan.

11. Danet, B. and Katriel, T. No two alike: play and aesthetics in collecting. Play and Culture 2, 3 (1989), 255-71.

12. Dannefer, D. Rationality and passion in private experience: modern consciousness and the social world of old-car collectors, Social Problems 27, (1980), 392-412.

13. Denegri-Knott, J., Watkins, R. and Wood, J. Transforming digital virtual goods into meaningful possessions. In $\mathrm{M}$. Molesworth and J. Denegri-Knott (Eds.), Digital Virtual Consumption (pp. 76-91). Oxford: Routledge, 2012.

14. Douglas, M. and Isherwood, B. The World of Goods: Towards an Anthropology of Consumption. 2nd ed. London: Routledge, 1996.

15. Gregson, N. Living with Things: Ridding, Accommodation, Dwelling. Sean Kingston Publishing, 2007.

16. Hogan, B. The presentation of self in the age of social media: distinguishing performances \& exhibitions online. Bulletin of Science, Technology \& Society, 30, (2010), 377-386.
17. Kaye, J. et al. 2006. To have and to hold: exploring the personal archive. In Proc. CHI 2006, 275-284.

18. Lehdonvirta, V., Wilska, T. and Johnson, M. Virtual consumerism: case habbo hotel. Information, Communication \& Society 12, 7 (2009), 1059-1079.

19. Linder, R., Snodgrass, C. and Kerne, A. Everyday ideation: all of my ideas are on Pinterest. In Proc. CHI 2014, ACM Press (2014), 2411-2420.

20. Lindley, S., Marshall, C.C., Banks, R., Sellen, A. and Regan, T. Rethinking the web as a personal archive. In Proc. WWW 2013, 749-760.

21. Martin, P. Popular Collecting and the Everyday Self: The Reinvention of Museums? London: Leicester Press, 1999.

22. McCracken, G. Culture and Consumption: New Approaches to the Symbolic Character of Consumer Goods and Activities. Bloomington: Indiana Univ. Press, 1988.

23. Molesworth, M. and R. D. Watkins. Adult Videogame Consumption as Individualized Episodic Progress. Journal of Consumer Culture. (Forthcoming)

24. Odom, W., Sellen, A., Harper, R. and Thereska, E. 2012. Lost in translation: understanding the possession of digital things in the Cloud. In Proc. CHI 2012, ACM, 781-790.

25. Odom, W., Zimmerman, J. and, Forlizzi, J. Teenagers and their virtual possessions: design opportunities and issues. In Proc. CHI 2011, ACM Press (2011), 1491-1500.

26. Odom, W., Zimmerman, J., Forlizzi, J. Placelessness, spacelessness, and formlessness: experiential qualities of virtual possessions. In Proc. DIS 2014, ACM Press (2014), 985-994.

27. O’Hara, K., Kindberg, T., Glancy, M., Baptista, L., Sukumaran, B., Kahana, G., \& Rowbotham, J. (2007). Collecting and sharing location-based content on mobile phones in a zoo visitor experience. CSCW, 16(1-2), pp. 11-44.

28. Pearce, S.M. The urge to collect. In Pearce, S.M. (Ed), Interpreting Objects and Collections (pp. 157-159). Routledge: New York, 1994.

29. Pearce, S.M. Collecting in Contemporary Practice. London: Sage, 1998.

30. Shankar, A. Identity and Consumption: An Interpretive Study of People and Their Record Collections. Unpublished doctoral thesis, 2002.

31. Siddiqui, S., \& Turley, D. Extending the self in a virtual world. Advances in Consumer Research 33, 1 (2006), 647648.

32. Spiggle, S. Analysis and interpretation of qualitative data in consumer research, Journal of Consumer Research 21 (December 1994), 491-503.

33. Thompson, C. Interpreting consumers: a hermeneutical framework for deriving marketing insights from the texts of consumers' consumption stories, Journal of Marketing Research, 34 (November 1997), 438-55.

34. Watkins, R. \& Molesworth, M. Attachment to digital virtual possessions in videogames. Research in Consumer Behavior 14, (2012), 153-171. 